CLINICAL REPORTS

\title{
Blood dyscrasias and mianserin
}

\author{
P. C. ADAMS \\ B.A., M.R.C.P. \\ M. M. REID \\ M.D., M.R.C.P.
}

ANGELA ROBINSON M.B.

\author{
M. C. VISHU* \\ M.D., M.R.C.P.
}

\author{
M. LIVINGSTON $\dagger$ \\ M.B., M.R.C.Psych. \\ Departments of Medicine and Haematology, Royal Victoria Infirmary, Newcastle upon Tyne, \\ *Department of Medicine, Cumberland Infirmary, Carlisle and \\ †University Department of Psychological Medicine, Gartnavel Royal Hospital, \\ 1055 Great Western Road, Glasgow
}

\begin{abstract}
Summary
Four cases are described in which the drug mianserin was implicated in the development of leucopenia. In one case this was accompanied by fatal aplastic anaemia. In a second, generalized bone marrow depression occurred, although leucopenia was the only clinically significant manifestation. Mianserin may depress bone marrow function and haematological surveillance is appropriate for patients taking this drug.
\end{abstract}

KEY WORDS: mianserin, leucopenia, bone marrow.

\section{Blood dyscrasias and mianserin}

The tetracyclic antidepressant mianserin is now widely prescribed, particularly in the elderly. Adverse reactions are generally few and no fatality has previously been reported with its use. We have seen four cases in which blood dyscrasias developed in patients being treated with mianserin. There was evidence of recovery in all after mianserin was discontinued but, unfortunately, one patient died.

\section{Case reports}

\section{Case 1}

A 52-year-old woman presented with an eight day history of bruising, bleeding gums and epistaxis, and

Reprints from: Dr. P. C. Adams, Freeman Hospital, Newcastle upon Tyne NE7 7DN. malaise for three days. Twelve weeks before admission she had taken an overdose of salbutamol tablets. Two weeks later treatment with mianserin $30 \mathrm{mg}$ at night was started for symptoms of anxiety and depression. Poor compliance was suspected and she was admitted to a psychiatric unit where she received mianserin $90 \mathrm{mg}$ at night, with temazepam $20 \mathrm{mg}$ at night and occasional paracetamol. Her blood count on admission to the psychiatric unit was normal. She received no other treatment and had had no other illnesses in the three months before presentation.

On examination she was pale with widespread petechiae. She was febrile and had signs of a left basal pneumonia, confirmed by chest radiography. Haemoglobin was $7.7 \mathrm{~g} / \mathrm{dl}$, with normal indices, white cell count $0.6 \times 10^{9} /$ litre, of which $1 \%$ were neutrophils and $99 \%$ lymphocytes. Platelets were less than $10 \times 10^{9} /$ litre. Bone marrow smears were very hypocellular, the only nucleated cells present being lymphocytes. Trephine biopsy revealed a very hypoplastic marrow, the majority of cells being erythroid and lymphoid. No megakaryocytes were seen.

Mianserin and temazepam were withdrawn and she was treated with gentamicin, flucloxacillin, penicillin and metronidazole, with resolution of her temperature. No fresh bleeding occurred so she received a blood transfusion only. Unfortunately, a fatal intracranial haemorrhage occurred suddenly five days after admission. The day before death her leucocyte count had risen to $6.9 \times 10^{9} /$ litre, suggesting her marrow had begun to recover. However, the 
post-mortem marrow histology was still markedly hypoplastic.

\section{Case 2}

A 69-year-old man presented with twelve days of pyrexia, rigors and oral ulceration. Eight weeks previously 'involutional melancholia' had been diagnosed, and he was treated with mianserin $30 \mathrm{mg}$ three times a day and $90 \mathrm{mg}$ at night with good effect. Full physical examination and blood count were normal at that time. He had had no other illnesses and had only received nitrazepam $20 \mathrm{mg}$ at night in addition to the mianserin in the three months before admission. On admission the temperature was $38.5^{\circ} \mathrm{C}$, there were oral ulcers and petechiae but no other abnormal physical signs. Haemoglobin was $12 \cdot 7 \mathrm{~g} / \mathrm{dl}$, with normal indices, white cell count $0.6 \times 10^{9} /$ litre, with neutropenia; $2 \%$ neutrophils, $89 \%$ lymphocytes, $5 \%$ monocytes, $3 \%$ eosinophils and $1 \%$ basophils. The platelet count was $330 \times 10^{9} / 1$. Bone marrow smears were hypocellular and were devoid of neutrophils and megakaryocytes. Trephine biopsy revealed marrow spaces containing virtually no haemopoietic cells. Occasional bone marrow fragments contained more erythroid and lymphoid cells and occasional megakaryocytes, but very few myeloid cells. Mianserin and nitrazepam were discontinued and he improved rapidly on gentamicin, ticarcillin and metronidazole. After five days he was afebrile and at eleven days his blood count was normal with a leucocyte count of $5.0 \times 10^{9} /$ litre, with $68 \%$ neutrophils. At follow-up four weeks later he was well. No known cause of marrow suppression was revealed by full investigation.

\section{Case 3}

A 41-year-old woman had been prescribed mianserin $20 \mathrm{mg}$ at night, and clobazam $10 \mathrm{mg}$ three times daily. Five weeks later she presented to her general practitioner with a one day history of fever, generalized aches and pains and a sore throat. She had marked cervical lymphadenopathy with inflamed pharyngeal and tonsillar walls, and was febrile. Cotrimoxazole, 2 tablets twice daily, was prescribed, and the next day, having taken no more than four cotrimoxazole tablets, a full blood count was performed which revealed an absolute neutropenia. She was admitted to hospital on the same day, where no other abnormal physical signs were detected. Full blood count in hospital revealed a haemoglobin of $11.5 \mathrm{~g} / \mathrm{dl}$, with normal indices. The total leucocyte count was $1.1 \times 10^{9} /$ litre, with $2 \%$ neutrophils, $6 \%$ eosinophils, $45 \%$ lymphocytes and $47 \%$ monocytes. The platelet count was $216 \times 10^{\circ} / 1$. Mianserin, clobazam and cotrimoxazole were discontinued and five days later the white cell count was $3.6 \times 10^{9} /$ litre, of which $23 \%$ were neutrophils, $12 \%$ monocytes, $6 \frac{\bar{C}}{\mathrm{C}}$ eosinophils and 59\% lymphocytes. Four days later the white count was $5.4 \times 10^{9} /$ litre, of which $50 \%$ were neutrophils. The return of the white cell coug to normal was accompanied by complete recovery. There was no evidence of any other known cause of agranulocytosis and there have been no major clit ical developments since her discharge from hospitaf

\section{Case 4}

A 68-year-old woman presented with persisterf occipital and frontal headache and symptoms sugges tive of a primary depressive illness. No organic cause was found for the headache and mianserin $30 \mathrm{mg}$ night was given. This was increased to $60 \mathrm{mg}$ at night three weeks later. Other therapy was glyceryl trinip trate $600 \mu \mathrm{g}$ sublingually as needed and butobarb tone $\mathbf{2 0 0} \mathrm{mg}$ at night as an hypnotic. She had hadg myocardial infarction five years before and also complained of persistent dyspepsia.

After five weeks treatment with mianserin, fum blood count demonstrated a total white count $\overrightarrow{\mathrm{ef}}$ $2.0 \times 10^{9} /$ litre, of which $7 \%$ were neutrophils, 75 lymphocytes and $18 \%$ monocytes. Haemoglobin we্दs $9.6 \mathrm{~g} / \mathrm{dl}$, with iron deficient indices. The platelet count was judged 'adequate' on film appearanges Her blood count five years before was nor 面䗆 although three years before mild iron deficiency been demonstrated. In view of her neutropeniog mianserin was discontinued. Two weeks later het leucocyte count was $3.7 \times 10^{9} /$ litre, with $46 \%$ neutro phils, $51 \%$ lymphocytes and the remainder basophis and monocytes. A month later it had risen $5.9 \times 10^{9} /$ litre of which $49 \%$ were neutrophils. Hae moglobin was still $9.4 \mathrm{~g} / \mathrm{dl}$. Unfortunately, the patient failed to attend for further appointments and was lost to hospital follow-up. No major problem has been notified to her general practitioner to date however.

\section{Discussion}

In Case 1, all marrow elements were depressed Thrombocytopenia was responsible for her deatlo After stopping mianserin there was a rise in the tota leucocyte count suggesting some marrow recover before death. There was no evidence of any systemis disease or other blood dyscrasia at post-mortem examination and cultures of blood, sputum, urines and multiple skin sites were sterile or only showe㧀 normal flora, suggesting that overwhelming infection was an unlikely cause of her marrow depression There was no evidence of viral hepatitis; posE mortem liver histology was normal. It seems likels? that mianserin caused her aplastic anaemia.

In Cases 2 and 3 , the clinical presentation was fairly typical of agranulocytosis. However, in Case 
marrow appearances again showed depression of both erythroid and megakaryocyte lines and we wonder if continued exposure would have produced pancytopaenia as in Case 1. Both patients recovered promptly on drug withdrawal. The only other drugs which could be implicated were benzodiazepines, and there is little evidence, despite massive worldwide use, that these agents can cause marrow suppression.

In Case 3, only four tablets of cotrimoxazole were taken before neutropenia was established, and it is highly unlikely that such profound neutropenia could have been caused so rapidly by this drug. We feel it likely, therefore, that mianserin was responsible for the neutropenia. Neutropenia undoubtedly occurred in Case 4 but fortunately caused no clinical problems. It again responded well to mianserin withdrawal. We did not feel re-challenge was appropriate in any of those cases and the evidence incriminating mianserin must, therefore remain circumstantial.

In six previous published cases, neutropenia had been ascribed to mianserin therapy (Curson and Hale, 1979; McHarg and McHarg, 1979; Adverse Drug Reactions Advisory Committee (of Australia), 1980). In two of these cases phenothiazines were also taken, although in one, the drug in question, prochlorperazine, was re-instituted with no further fall in leucocyte count. The Committee on Safety of Medicines has received reports of seven other cases of neutropenia occurring in patients receiving mianserin (Committee on Safety of Medicines, 1981a). In four of these there was thought to be a strong probability that the reaction was due to mianserin therapy. The reaction has been highlighted in a recent 'Current Problems' (Committee on Safety of Medicines, 1981b).

Mianserin is used widely in both hospital and general practice. Side effects of the severity described here demand that all patients receiving this drug should be followed carefully, with scrupulous attention being paid to the results of regular blood counts. Our experience underlines the importance of continued reporting of side effects of new drugs and reinforces the possibility that serious problems may arise with apparently safe substances. Careful reporting of all suspected adverse drug reactions to the Committee on Safety of Medicines remains the most reliable way of identifying adverse reactions which occur at low frequency, particularly when they mimic naturally occurring disease.

\section{Acknowledgments}

We would like to thank Dr D. W. Zutshi for his help and also the consultants under whose care these patients came. Thanks are also due to Mrs D. Naisby for invaluable secretarial assistance.

\section{References}

Adverse Drug Reactions Advisory Committee (of AUSTRALIA) (1980) Medical Journal of Australia, 2, 673.

Committee on SAfety of Medicines (1981a) Personal Communication.

COMMITTEe on SAFETY of Medicines (1981b) Mianserin and blood dyscrasias. Current Problems, 7, 1.

CURSON. D.A. \& HALE. A.S. (1979) Mianserin and agranulocytosis. British Medical Journal, 1, 378.

MCHARG. A.M. \& MCHARG. J.F. (1979) Leucopenia in association with mianserin treatment. British Medical Journal, 1, 623.

(Accepted 7 April 1982) 